\title{
Essentials of Drip Irrigation System for Saving Water and Nutrients to Plant Roots: As a Guide for Growers
}

\author{
Tawheed Mohammed Elheesin Shareef ${ }^{1,2}$, Zhongming Ma1*, Baowei Zhao ${ }^{3}$ \\ ${ }^{1}$ Gansu Academy of Agricultural Sciences, Lanzhou, China \\ ${ }^{2}$ Department of Agriculture Engineering, Faculty of Agriculture, University of Khartoum, Khartoum State, Sudan \\ ${ }^{3}$ School of Environmental and Municipal Engineering, Lanzhou Jaotong University, Lanzhou, China \\ Email: *mazhming@163.com
}

How to cite this paper: Shareef, T.M.E., Ma, Z.M. and Zhao, B.W. (2019) Essentials of Drip Irrigation System for Saving Water and Nutrients to Plant Roots: As a Guide for Growers. Journal of Water Resource and Protection, 11, 1129-1145.

https://doi.org/10.4236/jwarp.2019.119066

Received: July 30, 2019

Accepted: September 8, 2019

Published: September 11, 2019

Copyright () 2019 by author(s) and Scientific Research Publishing Inc. This work is licensed under the Creative Commons Attribution International License (CC BY 4.0).

http://creativecommons.org/licenses/by/4.0/

\begin{abstract}
Many regions around the world are characterized by limited water resources, where the average annual per capita renewable water is about 1000 - 1700 cubic meters. For instance, in China the problems of water supply are widely known globally. Though, China is facing main problem which is how to distribute water, instead of water shortage in itself. Therefore, restricted resources of water are increasingly stressed in the future by many factors such as excessive clouds of water, pollution and climate change. On the other hand, most studies have been indicated that the agricultural sector is one of the sectors that will face a large water deficit in the future due to the high demand for food, competition for water resources, drought and the high consumption of water due to the acquisition of traditional surface irrigation techniques. In spite of introducing modern irrigation methods such as drip irrigation in agriculture by developing irrigation methods and eliminating old traditional irrigation methods, however, its efficiency is related to the qualifying of farms and users of irrigation water, where they are the main users of irrigation water in water resources management. The considerable challenge facing agriculture is to raise irrigation efficiency depending on water-saving irrigation systems to provide water resources for crops. Therefore, the purpose of this study was to provide farmers with important points about using drip irrigation technology, to raise their technical level in using irrigation water, through their guidance to the best techniques and to avoid some common mistakes in design, utilization, management and maintenance of drip irrigation system, which could provide the scientific reference for applicationof drip irrigation.
\end{abstract}

\section{Keywords}

Drip Irrigation, Irrigation Efficiency, Water Saving, Emitters, Water 
Requirements

\section{Introduction}

In recent years, the modern irrigation systems application has taken great section in irrigation techniques and obtained substantial attention in the world, especially in developing countries. The significance of drip irrigation system is that it can provide more water, also meet the same requirements of the plants like the other techniques of irrigation systems [1]. Furthermore, the drip irrigation system reduces the water touch with the plants stem, leaves and fruit. Therefore, the water can only moisten a limited zone that is close, and directly to the plants roots zone. This will avoid several serious plant pathologies such as rotting plant parts (rot diseases) [1]. On the other hand, the emitters clogging has been a considered as a big problem which is facing drip irrigation systems, since it contains the high level of substances solids and nutrients which are accumulated inside drip lines, especially those related with the domestic or municipal wastewater when utilized in irrigation. Therefore, we must pay attention to it continuously [2]. Moreover, water management is a serious essential of irrigated crop production. Whereas water management and effective irrigation systems practices can help preserve farm profitability in the time of limited and high costs for the water supply. In addition, the effective water management may also decrease the effect of irrigated production on off-site water quality and quantity. Irrigation water is managed to save water supply, to decrease water quality effects, and to increase producer net returns [3]. Hence, saving and conservation of water through improving water management are considered an important topic of water requirements in the future. Therefore, the objectives of this study were: 1 ) to identify the most important factors and questions posed by farmers which are regarding the design and management of drip irrigation system, 2) to explain many items about drip irrigation system such as: definition of drip irrigation and its techniques; determination of the advantages of DIS, the components of DIS and its functions; the requirements for designing and effective management of DIS, 3) in addition, to supply drip irrigation system to extension research.

\section{What Is the Drip Irrigation System?}

\subsection{Definition of Drip Irrigation System (DIS)}

Drip irrigation is one of the modern irrigation methods for irrigation, a technique aimed to distribute water near the roots, in small quantities, in a concentrated and hesitant manner in order to maintain the soil moisture needed for the plants [4].

\subsection{Comparison of DIS with Other Techniques}

- In the case of surface irrigation techniques and sprinkler irrigation techniques, the plants are supplied with water to meet its requirements for a long 
period, sometimes exceeding more than one week. Therefore, that the plants take advantage of it excessively in the first days after irrigation, which leads to reduce in the quantity and quality of the product in addition to the significant loss of water and fertilizer [5].

- In the case of drip irrigation, water is distributed according to the daily requirements of plants in small quantities and concentrated in the roots zoon, which helps to obtained abundant product and with the high quality. Irrigation efficiency is calculated theoretically at the field level which as shows in (Figure 1).

\section{What Are the Advantages of Drip Irrigation System?}

\subsection{Advantages of Drip Irrigation}

\subsubsection{Economy of Using Water}

The high efficiency of drip irrigation is not only produced by the equipment's of drip irrigation, but also resulted from the two of main factors: a) the first factor is according to the water reaches to the plants roots with minimum evaporation and infiltration into the soil depth; b) the second factor is related to the water distributed according to the daily requirements for crops rather than tracking irrigation cycle. Furthermore, there are many advantages of drip irrigation such as: 1) it can irrigate only a limited patch of soil; 2) it can used with small quantities and low pressure; 3) it doesn't wet the plant leaves; 4) it can distribute the fertilizers with irrigation water (enriched irrigation); 5) it can be used the automatic techniques; 6) limited evaporation of water; 7) improve the quality and quantity of production [6]. In addition, drip irrigation is suitable for all types of soils, certified agriculture, the conditions of available water and the land shapes. Therefore, using drip irrigation system, could obtain high productivity for different crops, for example, the productivity per hectare which was recorded of some region around the world as shown in Table 1 [7]. In addition, when comparing modern irrigation methods (drip or Sprinkler) with surface irrigation method (furrow) to produce different crops, for example, the researcher Mohamed [8] found that there were significant differences between irrigation methods in terms of grain production and green weight, where the average of the two seasons of grain production were $(6.48,6.065$, and 7.905 tons/ha) for both drip irrigation and sprinkler and furrow respectively, and for the green weight, the average for the two seasons were $(24.4,22.04$, and 25.75 tons/ha) for drip, Sprinkler, and furrow irrigation respectively. Also the researcher Tagar [9] reported that the drip irrigation method saved $56.4 \%$ water and gave $22 \%$ more yield as compared to that of furrow irrigation method.

\subsubsection{Economic Cost in Production}

The utilization of drip irrigation methods could reduce the manpower, when using automatic instruments, thus, that one person can manage all the irrigation process. Also with drip irrigation can use the some special equipment such as 


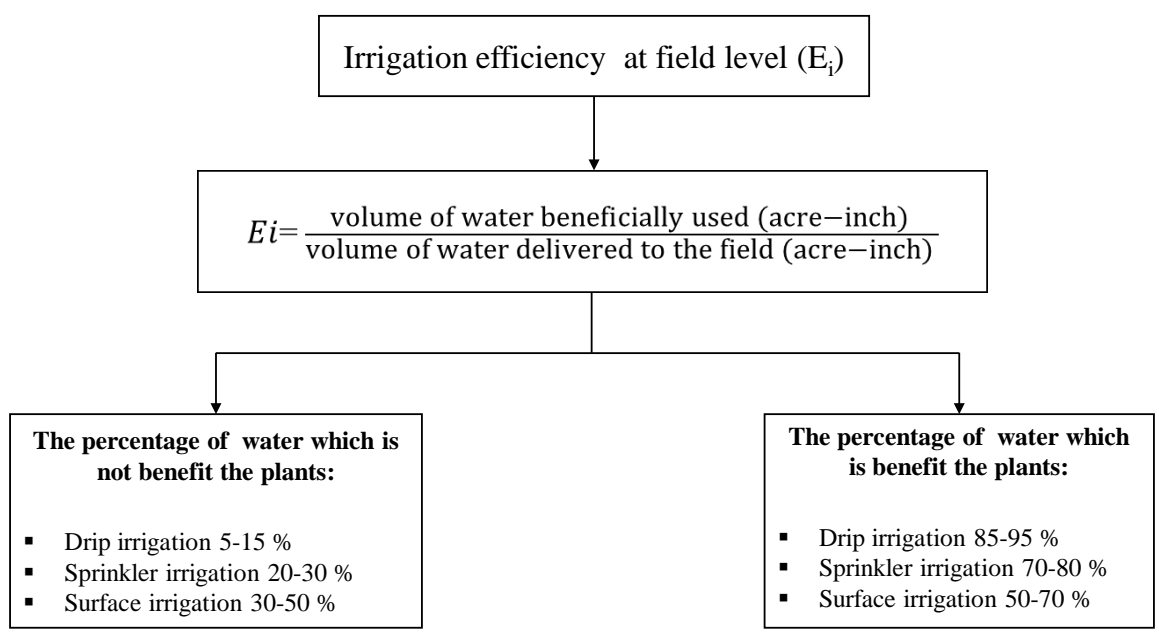

Figure 1. Irrigation efficiency.

Table 1 . The productivity tonnes per hectare.

\begin{tabular}{cc}
\hline The product & Productivity tonnes/hectare \\
\hline Tomatoes & 120 \\
Onions & 120 \\
Potato & 90 \\
Wheat & 84 \\
Watermelon & 50 \\
Grapes & 20 \\
\hline
\end{tabular}

black plastic films (plastic strips) which have several benefits such as earlier planting dates, soil moisture retention, weed management, reduction in the leaching of fertilizer, improved crop quality, reduction in soil compaction, and reduction in roots damage. On the contrary, in crop production there are disadvantages to using plastic films such as higher cost, environmental concern like the accumulation in soil, since the correct disposal and removal of these plastics are economically and technically burdensome [10] [11]. Figure 2 shows some images for plastic films which are used for agricultural applications [12].

\subsection{Disadvantages of Drip Irrigation System}

The most important constraints of drip irrigation are the high primary cost and adoption of advanced techniques, which is required that the farmers acquire some of essential skills. Consequently, among the experiences, it turns out that most of farmers they don't take the necessary precautions to complete projects. In addition, they lack the necessary skills to run drip irrigation equipment, which requires consultation of experts in the field. Figure 3 shows the process of disadvantages of drip irrigation. Furthermore, the drip irrigation has numerous disadvantages such as emitter clogging; compared with the sprinkler irrigation, water distribution into the soil is limited; the components of drip 


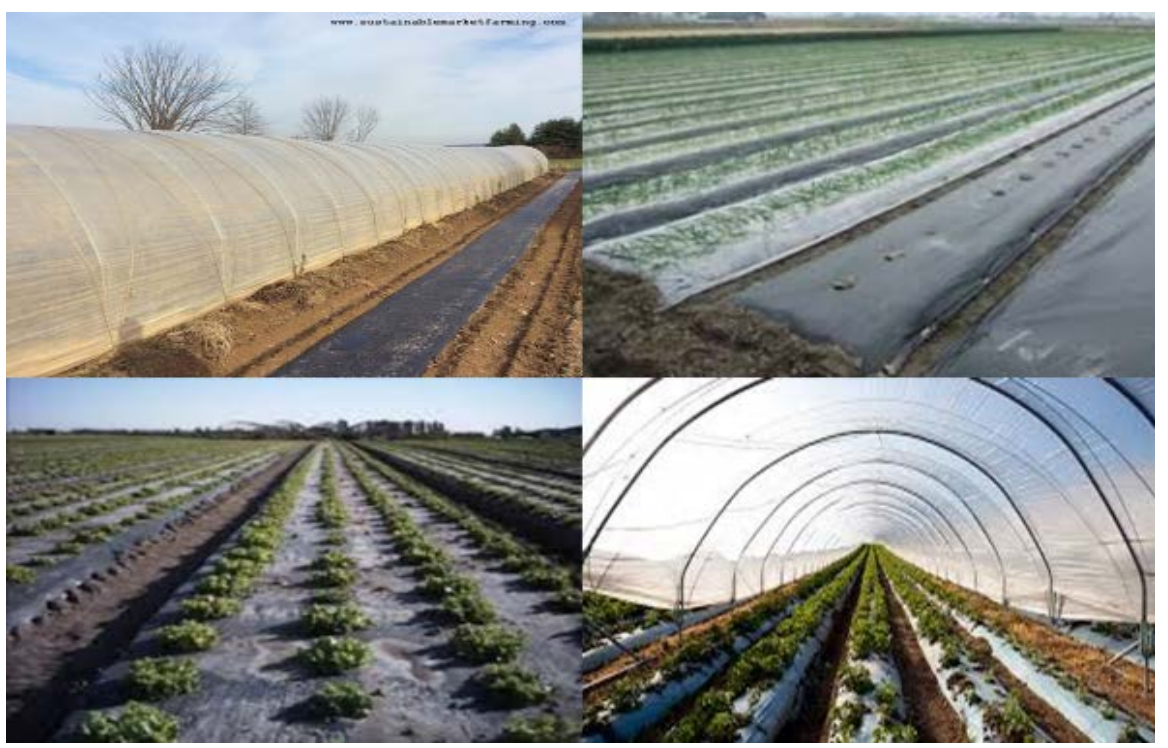

Figure 2. Application of plastic films.

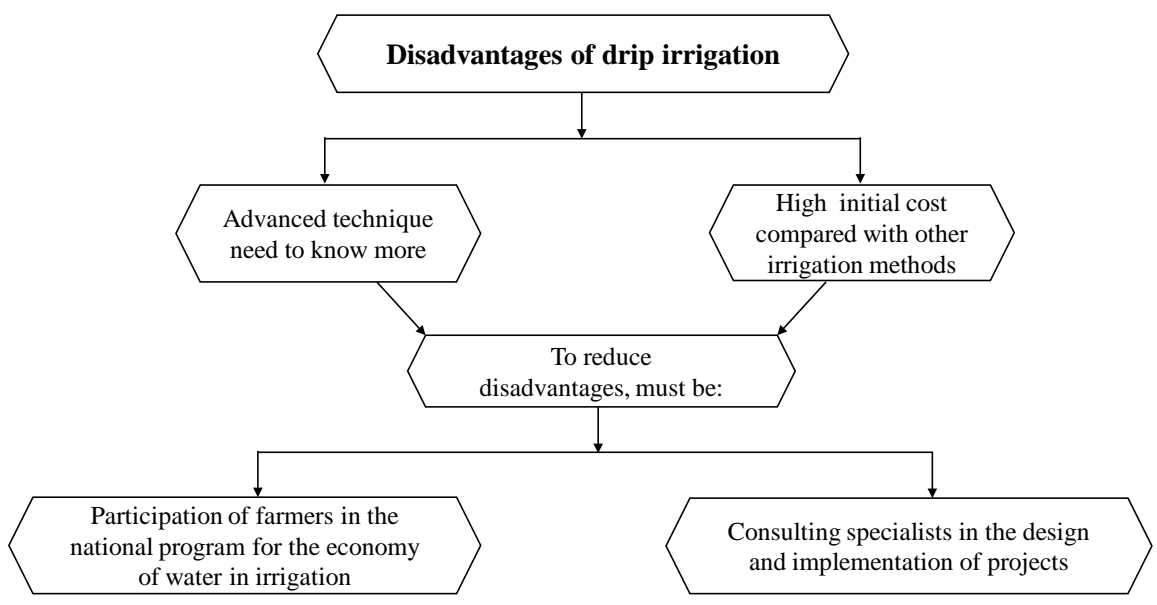

Figure 3. The process of disadvantages of drip irrigation.

system can be damaged by different items in the field such as machines, workers, and animals, etc. [13] [14].

\section{What Are the Conditions for Using Drip Irrigation System?}

The conditions of using drip irrigation system are associated with many factors such as (a) the quality of soil, (b) irrigation water quality, (c) the climatic conditions and (d) the species of the crops. As that the selection of the appropriate equipment's which are required by each situation is one of the reasons for success of the projects [15].

The quality of soil; in sandy/coarse soils, water infiltration tends to depth of soil (vertical distribution of water). In this case, should be used the emitters with low discharge and increasing the number of irrigation times per day to meet the water requirements of plants. In loam/medium soils, water infiltration be ba- 
lanced horizontally and vertically, therefore, in this case must be use the emitters with the medium discharge. In clay/fine soils, water infiltration is seep horizontally, in this case, should be use the emitters with medium or large discharge and the distance between emitters must be greater. Table 2 shows soil type and emitter considerations [16].

Irrigation water quality; there are many sources of water which determines the water quality that used in irrigation. Figure 4 shown the water purification based on source.

The sandy soils required small amounts of water in each irrigation time, with a high frequency. Whereas, the clay soils required large amounts of water in each irrigation time, with a low frequency. Accordingly, the concern of water requirements of plants, should require the control of appropriate water quantity in appropriate time and place. This leads to that fact of drip irrigation techniques can meet the requirements of plants with high accuracy.

The climatic conditions; the daily added quantities of irrigation water rely on water requirements of plants and climatic conditions, including the rainfall and temperature, which are leads to Irrigation network design and then irrigation programming.

The species of the crops; drip irrigation technique can be used to irrigate all plants including wheat, corn, tomatoes, and potatoes and so on [17].

\section{What Are the Components of Drip Irrigation System Networks?}

The required components of drip irrigation system include the pumping station, main lines, sub main lines, lateral lines, emitters, valves, fitting and other significant accessories [18], which are shown in Figure 5.

\subsection{Pumping Station}

The pumping unit comprises of the power unit and a centrifugal deep, submersible pump and accessories. The main requirement in the design and selection of pumping equipment for drip irrigation system is the high efficiency.

\subsection{Fertilizers Equipment's}

Technique of fertilizer is utilized to apply the chemicals with irrigation water, where the chemicals include (pesticides, fertilizers, and anti-clogging factors).

Table 2. Soil type and emitter considerations.

\begin{tabular}{|c|c|c|}
\hline Soil type and texture & Wetting pattern & Drip emitter spacing \\
\hline Sand/coarse & & $30.48 \times 30.48 \mathrm{~cm}$ \\
\hline Loam/medium & & $45.72 \times 45.72 \mathrm{~cm}$ \\
\hline Clay/fine & & $60.96 \times 60.96 \mathrm{~cm}$ \\
\hline
\end{tabular}




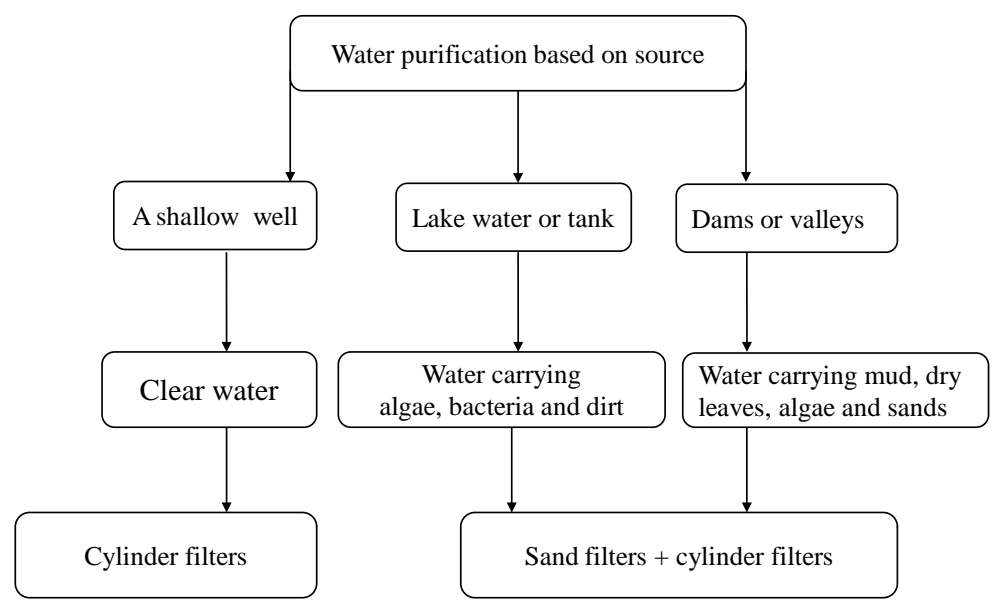

Figure 4. Water purification based on source.

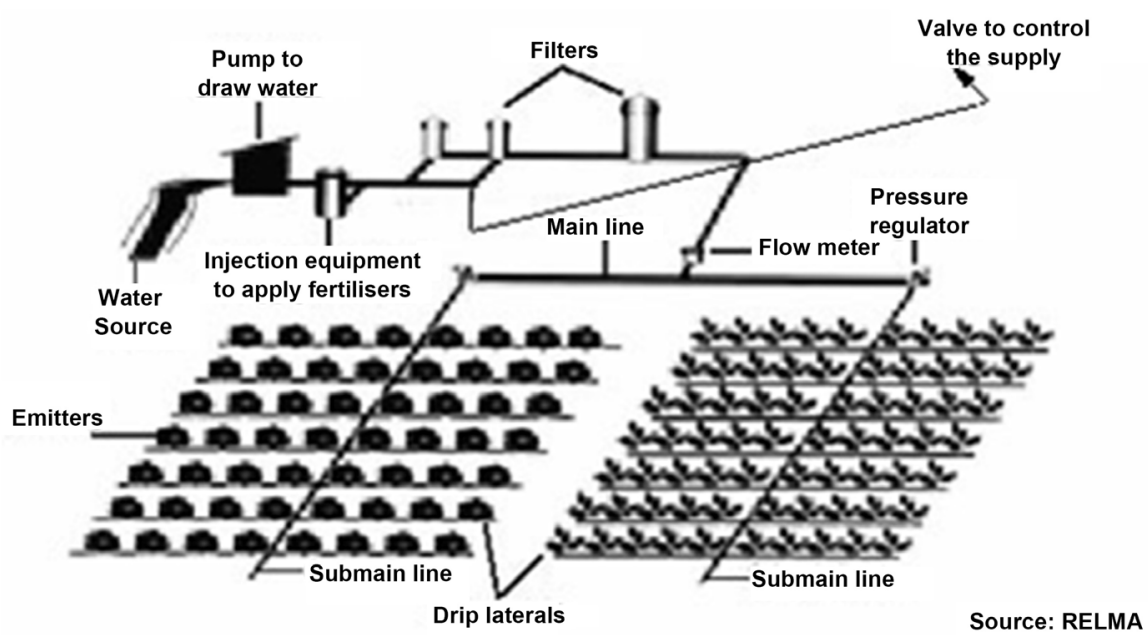

Figure 5. An example layout of drip irrigation system.

This technique is named fustigation, and there are different methods for performing fustigation (fertigation) [19] [20]. Besides, fertilizer system involves of fertilizer tank, venture injector, and Injector pump.

\subsection{Filtration Unit}

Filtration unit is the important unit of drip system. Where the disc filter or screen filter can be used for municipal water or wells, and there are some filters possess a valve to open and flush the filter. In spite of these techniques have high cost, but they are trustworthy and easy to clean. On the other hand, it should be noted that the sand filters are very important for open water sources or any surface water sources [21].

\subsection{Valves}

Valves are the most important to control the flow of water into the system of drip irrigation. There are many types of valves such as air vacuum relief valves and pressure-regulating valves [22] [23]. 


\subsection{Pressure Gauge}

Pressure gauges are extremely significance to monitor the operation of compressed irrigation systems, in order to maintain the continuity of the system with the correct pressure.

\subsection{Main Line}

The main line is a considered as the considerable pipeline diameter in irrigation network, which is deliver water under hydraulic conditions that is the proportional to the flow speed and loss of friction in order to convey the water to the sub main-line. Generally, the pipes used in this type are made of PVC, galvanized light steel or the black high density polyethylene (HDPE) which are buried permanent. In addition, the sizes of pipes rely on the farm area and design system [4] [24].

\subsection{Sub-Main Line}

The sub-main pipe lines are made of the same type as the main lines, which are smaller diameter pipe lines extend from the main line to the different plots at the field level to distribution the irrigation water [25].

\subsection{Lateral Lines}

The lateral lines are made of liner low density polyethylene tubing (LLDPE) available in black which are used for conveying water from the sub main line to the emitters devices, and then to the plants roots zone. These lines can be placed as surface lines or subsurface lines, which are called polyethylene (P.E) tubes [26] [27].

\subsection{Emitters/Drippers}

The drip emitters are considered as the main heart of the drip irrigation system, which are convey directly the small amounts of water to plants roots zone, in order to improve soil moisture with least amount of water lost due to runoff, evaporation and wind [28]. The main division of drip emitters as follows: on-line drippers and in-line drippers, where there are a lot of types of emitters. Furthermore, the drip emitters include four various operating features that contain turbulent flow, pressure compensation, adjustable flow, and vortex. Figure 6 as shown some types of drip emitters.

\section{What Are the Conditions for Success of Drip Irrigation System Projects?}

1) Proper design of the project; drip irrigation is a permanent system that is developed to be able to meet the requirements of plants in all conditions which the plants passes throughout the crop cycle. In addition, it is difficult to change because it must be carefully designed since the beginning. On the other hand, can't be accomplished without prior technical and economic study by specialized 


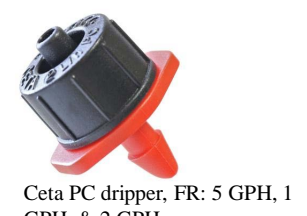

Ceta PC dripper,
GPH, \& 2 GPH

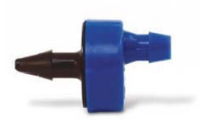

Xeri-Bugs emit water at rates of $0.5,1.0$ and 2.0 gallons-per-hour (GPH)

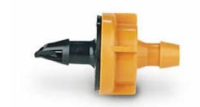

PC24 - Pressure-Compensating Module - Barb Inlet, 24.0 GPH, Orange

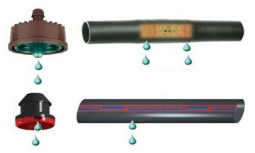

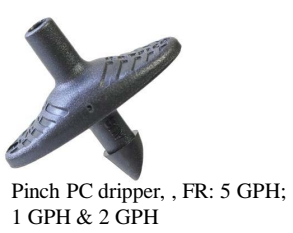

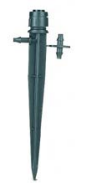

XS360TSPYK - Xeri-Spray 360 True Spray - 5 in. Spike

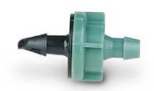

PC10 - Pressure-Compensating Module - Barb Inlet, 10.0 GPH

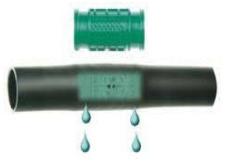

Inline emitters

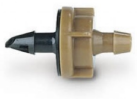

Barb Inlet, PC, FR: $12.0 \mathrm{GPH}$

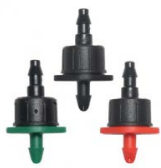

CETA PC Emitters, 3 different flows, have $1 / 4$ " barbs on the inlet and outlets

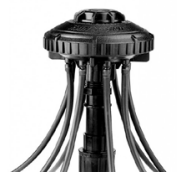

Xeri-Bird 8 Multi-Outlet, Filter \& 7 Removable Port Plugs, FR: 0.5 to $24 \mathrm{GPH}$

Outlet Chamber

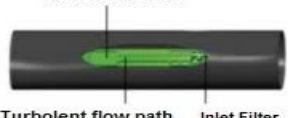

Figure 6. Types different drip emitters.

experts. Therefore, any system not guaranteed the expected services it becomes useless when used. More ever, these important points are identified as follows: a) by identifying the requirements of plants and available water resources, b) by determine the system of measurements and equipment's, c) by testing appropriate and efficient equipment and manage and controlling of irrigation, d) distribution of water quantities to avoid the lose water through infiltration into the soil, e) by rely on irrigation times with a few amounts and frequent, f) monitoring of soil moisture continuously [29].

2) Good maintenance of irrigation system; the sustainability and efficiency of the drip irrigation system is dependent on maintenance of the equipment's such as; maintenance and purification of the filters, controlling of flow of drippers, washing the pipes during the season, washing the whole irrigation network at least at the beginning and the end of the season.

3) Control of water distribution; the distribution of water from the center of the irrigated unit is better than its distribution from one side [30]. As shown in (Figure 7), the drippers which are placed in the area with high pressure its better than that placed in the area with low pressure. In addition, the irrigation network must be operated at least 24 hours after the end of the works, then washed and cleaned from all dirties and dust. Besides, pipes should not be covered and buried, except only after making sure are free of any cracking or malfunction in the installation process.

\section{What Are the Water Requirements of Plants?}

Figure 8 shows in short the steps of the water requirements of plants, which that 


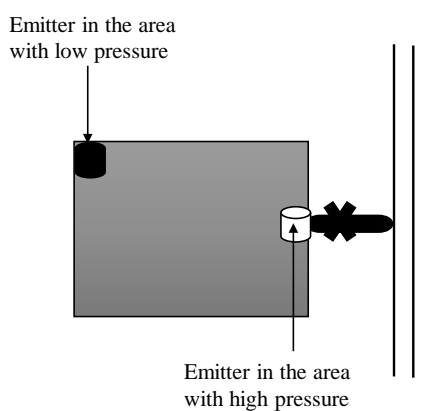

(a) Distribution from the center

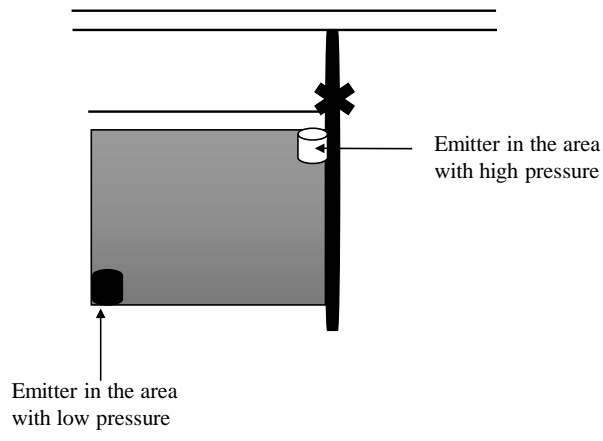

(b) Distribution from the one side

Figure 7. Control of the water distribution.

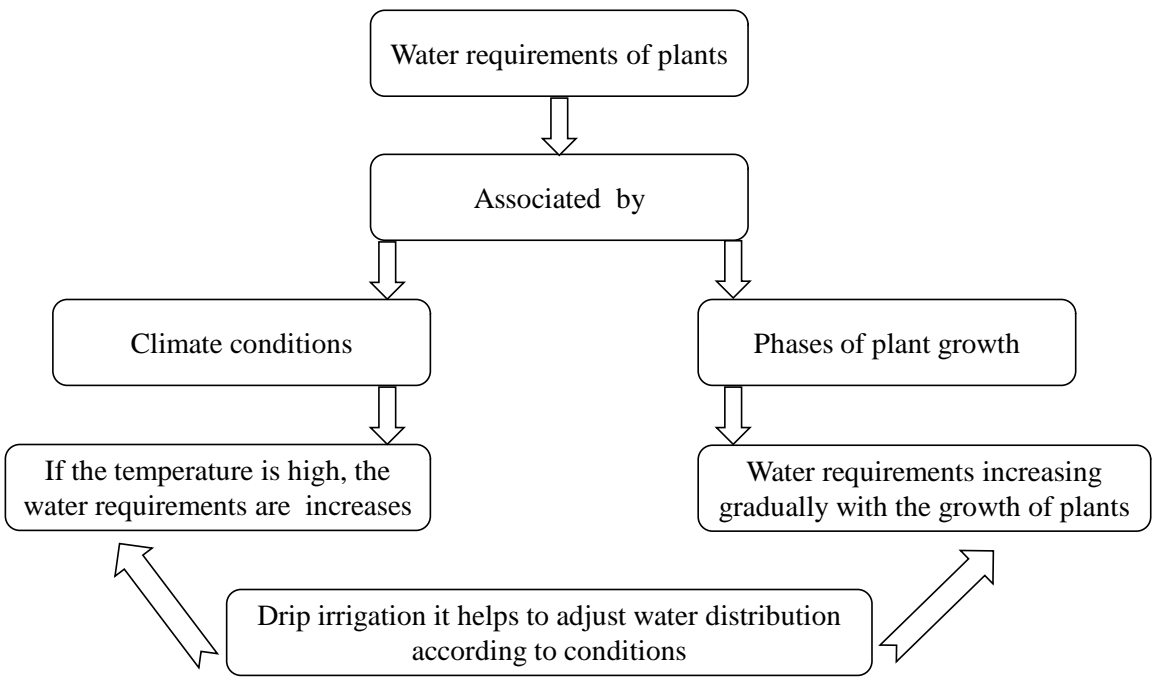

Figure 8. Steps of the water requirements of plants.

are depending on the important factors such as climate conditions, plant growth stages [31] [32]. Furthermore, (Table 3) is shown the appropriate time to give 10 cubic meters of water according to the distance between lines.

To explain and use the above table: if the water requirements of plants are 10 $\mathrm{m}^{3}$ of water per hectare, the distance between lines is one meter, and the distance between the emitters is 0.40 meters consequently, the irrigation time will be 12 minutes. Whereas, if the water requirements of plants are $20 \mathrm{~m}^{3}$ of water per hectare, the irrigation time will be 24 minutes.

\section{What Are the Appropriate Agricultural Techniques for Drip Irrigation System?}

1) Determination of the distance between lines and plants; drip irrigation has no restriction or condition on the distance between lines or plants, and the specificities of these dimensions particularly rely on the type of plant and soil quality [33]. For example Table 4. \& Figure 9 show the distance between lines and plants for different types of plants under drip irrigation system. 
Table 3. The appropriate time to give $10 \mathrm{~cm}^{3}$ of water.

\begin{tabular}{crrrrr}
\hline Distance between lines & 0.8 & 1 & 1.2 & 1.5 & 2 \\
Emitters flow rates 1/h & 2 & 2 & 2 & 2 & 2 \\
\hline Distance between emitters & $0.4 \mathrm{~m}$ & & & & \\
\hline Duration of irrigation required per minute & 10 & 12 & 14 & 18 & 24 \\
\hline Distance between emitters & $0.33 \mathrm{~m}$ & & & & \\
\hline Duration of irrigation required per minute & 8 & 10 & 12 & 15 & 20 \\
\hline
\end{tabular}

Table 4. The distance between lines and plants (m) under drip irrigation system.

\begin{tabular}{cccccc}
\hline & \multicolumn{3}{c}{ Individual drip lines } & \multicolumn{3}{c}{ Double drip lines } \\
\cline { 2 - 6 } Types of plants & $\begin{array}{c}\text { Distance } \\
\text { between lines } \\
\text { (a) }\end{array}$ & $\begin{array}{c}\text { Distance } \\
\text { between plants } \\
\text { (b) }\end{array}$ & $\begin{array}{c}\text { Distance } \\
\text { between lines } \\
\text { (c) }\end{array}$ & $\begin{array}{c}\text { Distance } \\
\text { between plants } \\
\text { (d) }\end{array}$ & $\begin{array}{c}\text { Distance between } \\
\text { Double lines } \\
\text { (e) }\end{array}$ \\
\hline Tomato & 1.2 & 0.5 & 1.5 & 0.5 & 0.3 \\
Potato & 0.8 & 0.3 & 1.2 & 0.3 & 0.3 \\
Maize & 0.8 & 0.25 & 1.2 & 0.25 & 0.3 \\
Wheat & 0.8 & - & - & - & - \\
Medicago spp & 0.8 & - & - & - & - \\
\hline
\end{tabular}

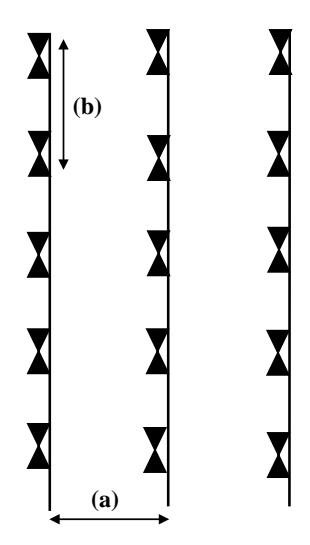

Individual lines

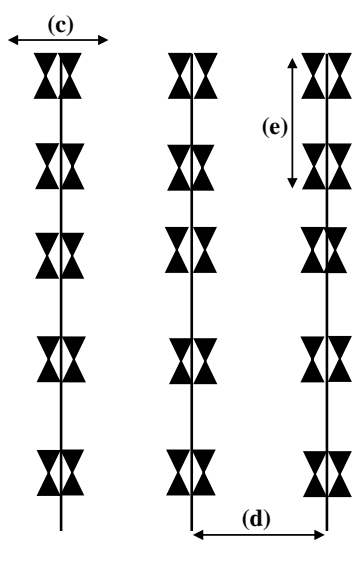

Double lines

Figure 9. The distance between lines and plants.

As for the major crops such as (wheat, medicago spp), the ranges of distance between lines from $0.8 \mathrm{~m}$ for heavy soil to $0.6 \mathrm{~m}$ for sandy soil.

2) Soil service; the method of drip irrigation it requires a good soil service and removal of all the obstacles which that cause poor distribution of irrigation water. As well as, soil analysis is the most important in using of drip irrigation system, because it helps to determinate the quantities of fertilizer required, which vary according to plant quality, growth period and soil quantity.

3) Mulching film or plastic cover soil; mulching films have many benefits such as; soil moisture conservation, rising of soil temperature, and prevent the 
growth of weeds. Thus, all of these can helps to increases the quantity of the product and improve its quality [34] [35].

\section{How to Maintain the Drip Irrigation Network and Resistance Clogging of Emitters}

The modern irrigation systems, especially drip irrigation, are considered of high cost, therefore, must be taken care of, and maintained properly in order to use for long time. Furthermore, Irrigation water usually has a poor quality due to salts and solid suspended materials, which are causing emitters clogging [36].

1) Maintenance of drip irrigation system: there are many items needs to maintenance in drip irrigation network such as; a) water tank; the bottom of water tank and its walls must be constantly cleaned from dust and solids, before passing through the irrigation channels, b) the pumping unit needs to constant maintenance, such as lubrication and change it if necessary, as well as the air filters and oil filters must be constantly cleaned. The pumping unit should be put it in a place that protects it from rain, direct sunlight, and installed on a high concrete base on the ground, c) filter unit; it is usually consisted of sand filters and filters with sieves or cylinders that can be used to purify the water before passing it to the channels. Therefore, should be washed periodically according to the amount of mud and suspended solids in the water.

On the other hand, it is necessary to put a water meter and pressure gauge before and after the cleaning station, in order to determine the problems which that may occur as a result of the increase or decrease in the amount of water or pressure, d) fertilization equipment's; usually consists of: tank for dissolving fertilizers in water; injector for fertilizers; fertilizers mixing machine; sub-equipment such as channels and filters, e) irrigation channels network; it is recommended to buried the main channels under surface of soil, so as not to be affected by sunlight. And also sub-channels and small pipes should be placed in a shaded place away from the moisture at the end of the agricultural season, and must be washed from time to time. In addition, fertilizer should always be injected before the final filters in order to avoid clogging of emitters with non-soluble fertilizers. As well as cleaning the tank of fertilizers before each operation and maintaining the fertilizer injector with cleaning from time to time especially at the end of the irrigation season, by running it with pure water only [37].

2) Resistance of clogging emitters: the phenomenon of emitters clogging is one of the biggest problems facing the use of drip irrigation system, because the water is conveyed in small quantities and low pressure through the small orifices of the water dispensers and thus it is easy to get clogged with the mineral particles (sand, clay), organic matter (insects, animals, algae, etc.) or chemical deposits. To find out the reasons of clogging, should be open the end of one of the sub-irrigation pipe or open the emitters, and collect the samples of the sediments to determine the type of these materials [2].

In order to resist the clogging, the following actions should be taken; a) pre- 
vent the passage of dirt and suspended materials in the water by the installation of filters with cylinders when used the well water, and installation of sand filters and filters with cylinders when used the water of reservoirs and dams, b) treatment of deposits of mineral salts; deposits of mineral salts especially calcium salts, can be found in a white form of layer which is adhering to the inner walls of the irrigation pipes and emitters. Thus, to treat mineral deposits, it is recommend added phosphoric acid to the irrigation water and running the irrigation system for 60 to 30 minutes, after that should be stopped the irrigation process for 24 hours and then washed the pipes. On the other hand, the emitters can also clog by algae which is growing on water surface and easily can be accumulated in water tanks and then in the pipes. consequently, for the treatment of the deposition of organic matter, it is recommend added sodium hypochlorite $(\mathrm{NaOCl}$ or $\mathrm{NaClO}$ ) concentration (of 1 to 5 milligram per liter of active ingredient) to irrigation water, and the rate of addition should be one time every 15 days.

3) Preventive maintenance during the irrigation season: the following factors of the ideal preventive maintenance of drip irrigation systems should be taken; a) lubrication of mechanical components for irrigation systems, b) control of distributed amounts of water, c) washing the filters periodically, d) washing the emitters by injecting nitric or phosphoric acid one time every 15 days, e) monitoring the distribution of water one time every month by measuring the flow of emitters, f) monitoring pressure gauge, where the operation of irrigation network should be between 1 to 1.2 bar, g) monitoring acidity and salinity of distributed water which is contained the fertilizers, $h$ ) emptying the pipes from the water, and wash them at the end of season, and i) don't mix unsuitable materials or fertilizers [38].

The process of fertilization and the addition of chemicals with irrigation water is the most important factor because it works to rationalize the use of water as well as supply the plants requirements of water in an easy and fast. Therefore, full solubility of fertilizers is considered as the most important factor of successful fertigation. In addition, in the matter of mixing fertilizers, there is no objection whatsoever to powder spreaders fertilizer on the soil directly before irrigation, however, it is not recommended to add urea with super phosphate at the same time. thus, when mixed with each other and preparation their solutions, must make sure that these fertilizers are compatible with each other and compatible with the irrigation water and type of irrigation system used [39] [40] [41]. Table 5 shows the fertilizers that can be mixed and that can't be mixed.

\section{Conclusion}

Drip irrigation is the modern technique to irrigate the crops. It conveys water only to the crop, decreasing the growth of weeds. The use of drip irrigation is the greatest water-conserving irrigation technique, with slight no wind-blown water and evaporation. Therefore, the study was pointed out many factors that the farmers need to care about them when used drip irrigation system. On the other 
Table 5. Compatible and incompatible fertilizers.

\begin{tabular}{|c|c|c|c|c|c|c|}
\hline & $\begin{array}{l}\text { Calcium chloride } \\
\qquad\left(\mathrm{CaCl}_{2}\right)\end{array}$ & $\begin{array}{l}\text { Potassium chloride } \\
(\mathrm{KCl})\end{array}$ & $\begin{array}{l}\text { Magnesium sulfate } \\
\left(\mathrm{MgSO}_{4}\right)\end{array}$ & $\begin{array}{l}\text { Potassium sulfate } \\
\qquad\left(\mathrm{K}_{2} \mathrm{SO}_{4}\right)\end{array}$ & $\begin{array}{l}\text { Potassium nitrate } \\
\qquad\left(\mathrm{KNO}_{3}\right)\end{array}$ & $\begin{array}{l}\text { Calcium nitrate } \\
\left(\mathrm{Ca}\left(\mathrm{NO}_{3}\right)_{2}\right)\end{array}$ \\
\hline $\begin{array}{l}\text { Ammonium sulfate; } \\
\qquad\left(\mathrm{NH}_{4}\right)_{2} \mathrm{SO}_{4}\end{array}$ & No & Yes & Yes & Yes & Yes & No \\
\hline $\begin{array}{l}\text { Magnesium nitrate } \\
\left.\qquad \operatorname{Mg}\left(\mathrm{NO}_{3}\right)_{2}\right)\end{array}$ & Yes & Yes & Yes & Yes & Yes & Yes \\
\hline $\begin{array}{l}\text { Calcium nitrate } \\
\quad\left(\mathrm{Ca}\left(\mathrm{NO}_{3}\right)_{2}\right)\end{array}$ & Yes & Yes & No & No & Yes & - \\
\hline Potassium nitrate $\left(\mathrm{KNO}_{3}\right)$ & Yes & Yes & Yes & Yes & - & Yes \\
\hline Potassium sulfate $\left(\mathrm{K}_{2} \mathrm{SO}_{4}\right)$ & No & Yes & Yes & - & Yes & No \\
\hline $\begin{array}{l}\text { Magnesium sulfate } \\
\qquad\left(\mathrm{MgSO}_{4}\right)\end{array}$ & No & Yes & - & Yes & Yes & No \\
\hline
\end{tabular}

hand, emitter clogging is considered as a big problem with importance of cost consequences and production. Therefore, technical guidelines for system managements should be adopted and followed. Finally, water is very important and necessary and must be placed in the priorities of our economic plans. So we recommend by using drip irrigation because of its advantages; rationalization in the behavior of water consumption and reducing the loss of water use; training and technical rehabilitation of farmers on the use of modern technologies in irrigation in terms of operation, maintenance and management.

\section{Acknowledgements}

Acknowledgements and especial thank to the Gansu Academy of Agricultural Sciences, Lanzhou, Gansu, China, 730070 for supporting this work.

\section{Conflicts of Interest}

The authors declare no conflicts of interest regarding the publication of this paper.

\section{References}

[1] Paul, J.C., Mishra, J.N., Pradhan, P.L. and Panigrahi, B. (2013) Effect of Drip and Surface Irrigation on Yield, Water-Use-Efficiency and Economics of Capsicum (Capsicum annum L.) Grown under Mulch and Non-Mulch Conditions in Eastern Coastal India. European Journal of Sustainable Development, 2, 99-108. https://doi.org/10.14207/ejsd.2013.v2n1p99

[2] Feng, J., Li, Y., Wang, W. and Xue, S. (2018) Effect of Optimization Forms of Flow Path on Emitter Hydraulic and Anti-Clogging Performance in Drip Irrigation System. Irrigation Science, 36, 37-47. https://doi.org/10.1007/s00271-017-0561-9

[3] Valipour, M. (2017) Global Experience on Irrigation Management under Different Scenarios. Journal of Water and Land Development, 32, 95-102. https://doi.org/10.1515/jwld-2017-0011

[4] Pair, C.H., Hinz, W.W., Reid, C. and Frost, K.R. (1975) Sprinkler Irrigation.

[5] Sammis, T.W. (1980) Comparison of Sprinkler, Trickle, Subsurface, and Furrow Irrigation Methods for Row Crops. Agronomy Journal, 72, 701-704. https://doi.org/10.2134/agronj1980.00021962007200050002x 
[6] Lamm, F.R. (2002) Advantages and Disadvantages of Subsurface Drip Irrigation. International Meeting on Advances in Drip/Micro Irrigation, Puerto de La Cruz.

[7] http://www.fao.org/3/a-au674a.pdf

[8] Abubaker, M.S., Farouk, S., Ahmad, F.S. and Tayseer, M. (2006) Comparison of Modern Irrigation Methods (Drip, Sprinkler) with Surface Irrigation Method (Furrow) for Maize Production. Damascus University Journal for Agricultural Sciences, 22, 427-450.

[9] Tagar, A., Chandio, F.A., Mari, I.A. and Wagan, B. (2012) Comparative Study of Drip and Furrow Irrigation Methods at Farmer's Field in Umarkot. World Academy of Science, Engineering and Technology, 69, 863-867.

[10] Wittwer, S.H. (1993) World-Wide Use of Plastics in Horticultural Production. HortTechnology, 3, 6-19. https://doi.org/10.21273/HORTTECH.3.1.6

[11] Yaghi, T., Arslan, A. and Naoum, F. (2013) Cucumber (Cucumis sativus L.) Water Use Efficiency (WUE) under Plastic Mulch and Drip Irrigation. Agricultural Water Management, 128, 149-157. https://doi.org/10.1016/j.agwat.2013.06.002

[12] https://www.ecplaza.net/products/plastic-film-mulch-greenhouse-mulching-film 4 $\underline{335996}$

[13] Pei, Y., Li, Y., Liu, Y., Zhou, B., Shi, Z. and Jiang, Y. (2014) Eight Emitters Clogging Characteristics and Its Suitability under On-Site Reclaimed Water Drip Irrigation. Irrigation Science, 32, 141-157. https://doi.org/10.1007/s00271-013-0420-2

[14] Freels, L. (2013) Drip Irrigation System and Apparatus for Installation Thereof. U.S. Patent Application 13/226,240.

[15] Liu, H., Wang, X., Zhang, X., Zhang, L., Li, Y. and Huang, G. (2017) Evaluation on the Responses of Maize (Zea mays L.) Growth, Yield and Water Use Efficiency to Drip Irrigation Water under Mulch Condition in the Hetao Irrigation District of China. Agricultural Water Management, 179, 144-157.

https://doi.org/10.1016/j.agwat.2016.05.031

[16] Arbat, G.P., Lamm, F.R. and Kheira, A.A. (2010) Subsurface Drip Irrigation Emitter Spacing Effects on Soil Water Redistribution, Corn Yield, and Water Productivity. Applied Engineering in Agriculture, 26, 391-399. https://doi.org/10.13031/2013.29959

[17] Hanson, B.R., Fipps, G. and Martin, E.C. (2000) Drip Irrigation of Row Crops: What Is the State of the Art. 4th Decennial Symposium: National Irrigation Symposium, Phoenix, 391-400.

[18] Goldberg, D., Gornat, B. and Rimon, D. (1976) Drip Irrigation: Principles, Design and Agricultural Practices.

[19] Yan, X.L., Dai, T.F. and Jia, L.M. (2018) Evaluation of the Cumulative Effect of Drip Irrigation and Fertigation on Productivity in a Poplar Plantation. Annals of Forest Science, 75, 5. https://doi.org/10.1007/s13595-017-0682-6

[20] Abalos, D., Sanchez-Martin, L., Garcia-Torres, L., Van Groenigen, J.W. and Vallejo, A. (2014) Management of Irrigation Frequency and Nitrogen Fertilization to Mitigate GHG and NO Emissions from Drip-Fertigated Crops. Science of the Total Environment, 490, 880-888. https://doi.org/10.1016/j.scitotenv.2014.05.065

[21] Marr, C. and Rogers, D. (1993) Commercial Vegetable Production. Drip Irrigation for Vegetables. Kansas State University Agricultural Experiment Station and Extension Service.

[22] Nakayama, F.S. and Bucks, D.A. (2012) Trickle Irrigation for Crop Production: Design, Operation and Management (Vol. 9). Elsevier, Amsterdam. 
[23] Oman, W.S. and Oman, W.S. (1977) Irrigation Purge Valve. U.S. Patent 4,022,244.

[24] Benouniche, M., Zwarteveen, M. and Kuper, M. (2014) Bricolage as Innovation: Opening the Black Box of Drip Irrigation Systems. Irrigation and Drainage, 63, 651-658. https://doi.org/10.1002/ird.1854

[25] Yearbook, A.E. (1975) American Society of Agricultural Engineers. St. Joseph, Michigan.

[26] Molina-Martínez, J.M. and Ruiz-Canales, A. (2009) Pocket PC Software to Evaluate Drip Irrigation Lateral Diameters with On-Line Emitters. Computers and Electronics in Agriculture, 69, 112-115. https://doi.org/10.1016/j.compag.2009.06.006

[27] Cohen, A. (2001) Drip Irrigation Emitters. U.S. Patent 6,250,571.

[28] Kuper, M., Dionnet, M., Hammani, A., Bekkar, Y., Garin, P. and Bluemling, B. (2009) Supporting the Shift from State Water to Community Water: Lessons from a Social Learning Approach to Designing Joint Irrigation Projects in Morocco. Ecology and Society, 14, 19. https://doi.org/10.5751/ES-02755-140119

[29] Thompson, T.L., Pang, H.C. and Li, Y.Y. (2009) The Potential Contribution of Subsurface Drip Irrigation to Water-Saving Agriculture in the Western USA. Agricultural Sciences in China, 8, 850-854. https://doi.org/10.1016/S1671-2927(08)60287-4

[30] Levidow, L., Zaccaria, D., Maia, R., Vivas, E., Todorovic, M. and Scardigno, A. (2014) Improving Water-Efficient Irrigation: Prospects and Difficulties of Innovative Practices. Agricultural Water Management, 146, 84-94. https://doi.org/10.1016/j.agwat.2014.07.012

[31] Nouri, H., Beecham, S., Hassanli, A.M. and Kazemi, F. (2013) Water Requirements of Urban Landscape Plants: A Comparison of Three Factor-Based Approaches. Ecological Engineering, 57, 276-284. https://doi.org/10.1016/j.ecoleng.2013.04.025

[32] Jensen, M.E. (1968) Water Consumption by Agricultural Plants (Chapter 1).

[33] Çetin, Ö. and Uygan, D. (2008) The Effect of Drip Line Spacing, Irrigation Regimes and Planting Geometries of Tomato on Yield, Irrigation Water Use Efficiency and Net Return. Agricultural Water Management, 95, 949-958.

[34] Zhang, P., et al. (2017) Plastic-Film Mulching for Enhanced Water-Use Efficiency and Economic Returns from Maize Fields in Semiarid China. Frontiers in Plant Science, 8, 512. https://doi.org/10.3389/fpls.2017.00512

[35] Steinmetz, Z., Wollmann, C., Schaefer, M., Buchmann, C., David, J., Tröger, J., Muñoz, K., Frör, O. and Schaumann, G.E. (2016) Plastic Mulching in Agriculture. Trading Short-Term Agronomic Benefits for Long-Term Soil Degradation? Science of the Total Environment, 550, 690-705. https://doi.org/10.1016/j.scitotenv.2016.01.153

[36] Song, P., Li, Y., Zhou, B., Zhou, C., Zhang, Z. and Li, J. (2017) Controlling Mechanism of Chlorination on Emitter Bio-Clogging for Drip Irrigation Using Reclaimed Water. Agricultural Water Management, 184, 36-45. https://doi.org/10.1016/j.agwat.2016.12.017

[37] Narale, P.D., Rathore, N.S. and Kothari, S. (2013) Study of Solar PV Water Pumping System for Irrigation of Horticulture Crops. International Journal of Engineering Science Invention, 2, 54-60.

[38] Nakayama, F.S., Boman, B.J. and Pitts, D.J. (2007) Maintenance. In: Developments in Agricultural Engineering, Vol. 13, Elsevier, Amsterdam, 389-430. https://doi.org/10.1016/S0167-4137(07)80014-X

[39] Bueno-Delgado, M.V., Molina-Martínez, J.M., Correoso-Campillo, R. and 
Pavón-Mariño, P. (2016) Ecofert: An Android Application for the Optimization of Fertilizer Cost in Fertigation. Computers and Electronics in Agriculture, 121, 32-42. https://doi.org/10.1016/j.compag.2015.11.006

[40] Du, Y.D., Cao, H.X., Liu, S.Q., Gu, X.B. and Cao, Y.X. (2017) Response of Yield, Quality, Water and Nitrogen Use Efficiency of Tomato to Different Levels of Water and Nitrogen under Drip Irrigation in Northwestern China. Journal of Integrative Agriculture, 16, 1153-1161. https://doi.org/10.1016/S2095-3119(16)61371-0

[41] Luo, H.H., Zhang, Y.L. and Zhang, W.F. (2016) Effects of Water Stress and Rewatering on Photosynthesis, Root Activity, and Yield of Cotton with Drip Irrigation under Mulch. Photosynthetica, 54, 65-73.

https://doi.org/10.1007/s11099-015-0165-7

[42] Wu, J., Guo, W., Feng, J., Li, L., Yang, H., Wang, X. and Bian, X. (2014) Greenhouse Gas Emissions from Cotton Field under Different Irrigation Methods and Fertilization Regimes in Arid Northwestern China. The Scientific World Journal, 2014, Article ID: 407832. https://doi.org/10.1155/2014/407832 